\title{
Thinking Through the Architecture Studio: Two Models of Research
}

\author{
Michael Jasper, \\ University of Canberra, Australia
}

\begin{abstract}
This paper compares and contrasts two approaches to the university architecture studio as a contribution to discussions around design-led research. The first is the sequence of undergraduate studios undertaken under John Hejduk (1929-2000) at the Cooper Union for the Advancement of Science and Art, New York, the second, the postgraduate Urban Design Studio at Cornell University, Ithaca, as directed by Colin Rowe (1929-1999). Student work is used to illustrate studio character, project type, and the diversity of architectural-urban problems addressed, ranging from Hejduk's Nine Square, Cube, and Juan Gris studios to Rowe's grid and fragment studies, infill or completion problems, and overall field or city scale projects. The paper highlights important differences in scale and project type while at the same time revealing a shared pedagogical and philosophical belief in abstraction, autonomy, and formal exercises in contrast to studios which emphasize functional brief, site specific studies, structure or building systems. From this it is conjectured that the Hejduk and Rowe approaches constitute exemplary models of studio-based research in architecture.
\end{abstract}

Keywords: architecture studio, education, studio-based research, Colin Rowe, John Hejduk

\section{INTRODUCTION}

It is precisely these ideas ... that have been utilized as the generative forces for certain of the didactic and exploratory problems given students at Cooper Union... The architect starts with the abstract world, and due to the nature of his work, works toward the real world. The significant architect is one who, when finished with a work, is as close to that original abstraction as he could possibly be ... and that is also what distinguishes architects from builders (Hejduk, 1985, pp. 66-67)

\begin{abstract}
The strategies of a design studio will depend on attitudes taken up, on the one hand, towards research and, on the other, towards that still almost incredible constellation of novelties which emerged in the opening years of this century, towards what we think about the student discovering for himself and what we think about the student becoming immersed in a tradition of which he cannot be a part (Rowe, 1996b, p. 62)
\end{abstract}

The underlying argument of this paper is that the various activities of the university architecture studio are a form of experimentation and that together, and in certain instances, they constitute a practice of design-led research. An analysis of two exemplary approaches to the architecture studio will be used to develop a preliminary response to this proposition. The examples are John Hejduk's didactic and exemplary suite of studio problems unrolled at Cooper Union between 1964 and 2000, and the multi-decade effort of Colin Rowe's Cornell University graduate Urban Design Studio, run between 1963 and 1988. An analysis of the two studio practices provides a range of highly charged and differentiated approaches to architectural research undertaken in the design studio. Each is distinguished by singular kinds of architecturalurban problems, functional briefs, and a range of formal-spatial responses. An emphasis is made in each, it is claimed, on how to structure and run the design studio as a form of open-ended research. In both the Hejduk and Rowe studios, that is, the life of the studio project is a contained, finite phase in a larger, continuous pursuit with findings to be generalized as provisional outcomes awaiting further refinement. In this manner, it is proposed, a survey of their work contributes to current discussions around design-led or studio-based research generally, and that conducted in schools of architecture specifically. 


\section{SCHOLARLY CONTEXT}

Analytical and historical work on the university studio as a kind of architectural experimentation on key discipline-specific elements - whether of form, space, structure, or the process of composition - is limited. Where such effort has been made, the point of view has been generally descriptive or anecdotal and documentation of the work of the studio, especially over multiple years, not of immediate access.

For the student projects resulting from Hejduk's Cooper Union studios, there has been, exceptionally, a reasonable amount of primary and secondary documentation sufficient to warrant a survey of the results. In addition, the existence of the Architecture Archive of The Cooper Union provides a resource on student projects for scholars and researchers. Key secondary essays include those of Moneo 1980, Pérez-Gómez 1999, and Slutzky 1980.

Regarding the design work undertaken at Cornell University within the context of Colin Rowe's Urban Design Studio, a small but sufficiently representative series of publications from academic staff and former students, as well as the publication of a high number of student projects, provide a profile of that program's approach and the resulting studio findings.

Key secondary writings on Rowe's studio, and summary descriptions as well as some documentation of student work, can be found in Cooper 1983, Hurtt 1983, Maxwell 2012, Middleton 1980, Rowe 1996a and Rowe 1996b.

Different from other studies of the Cooper Union and Cornell studios, my paper focuses on the work of the studio itself, in particular on studio programs and student material produced, and less on the historical and intellectual contexts in which the studio was undertaken.

The research data was assembled from published sources and university archives. The material on Hejduk's studio teaching at Cooper Union has been taken from a number of key sources. These include On the Education of an Architect: A Point of View (Franzen et al., 1999), Moneo 1980, Slutzky 1980, and Hejduk 2011. Extensive use was made of the The Irwin S. Chanin School of Architecture Archive of The Cooper Union. Important additional material on Hejduk's parallel design investigations was sourced from the Collection Centre Canadien d'Architecture / Canadian Centre for Architecture, Montréal. The primary data and images related to the Cornell program were sourced from academic publications. Key primary sources are noted above.

These two studios provide a particularly apt beginning to a larger study of the university architecture studio due not only to the depth of data and project documentation available over multi-year periods, but importantly because they represent a range of scale and education level. Hejduk's studio, to generalize, focuses on the tectonic scale, Rowe's on the urban. The Cooper Union program, during the period under exam, is dedicated to undergraduate teaching, the Cornell program on postgraduate.

\section{ANALYSIS, FINDINGS}

In the following section, I examine the major thematic structure, key topics, and general approach to the Hejduk and Rowe design studio sequences. Differences in studio character, approach, design problem, and device are bracketed through a limited set of compositional and formal moves. Student work is used to illustrate specific responses.

\section{Studio Work at Cooper Union}

In his notes to accompany the publication of Fabrications, Hejduk recalls the role of the school of architecture specifically and the pedagogical emphasis in the teaching of fine arts generally.

The work of the school is one which exemplifies a "tradition of commitment to search for new relationships of forms - in our opinion the only possible, as well as necessary role of a school of architecture" (Hejduk, 1974, s.p.).

This is a useful starting point: 'to search for new relationships of forms' can be taken as one ambition behind the development of a sequence of studio problems refined over several decades by Hejduk and his colleagues at Cooper Union. An analysis of the architecture design studios reveal a commitment to abstract problems, to 'a belief in paradigmatic creation, that is, in the pedagogical use of exemplary or abstract problems, which however removed from real implementation or function, develops a heightened sense of consistency, a framework for inventiveness' (Slutzky, 1980, p. 86). The approach thus also aims to work the student's imagination.

Hejduk's specific studio sequence has been well documented. The 1971 monograph, Education of an Architect, provides a useful index of how studio problems were conceived, worked, and what was produced (Franzen et al., 1999). Three studios 


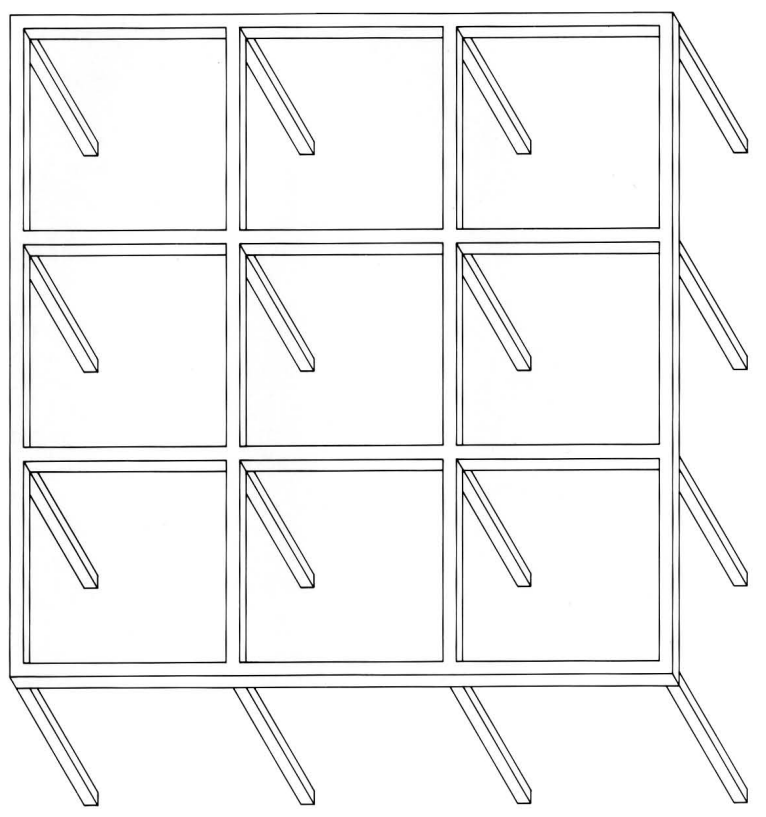

Figure 1: Nine Square Problem (Architectonics, The Nine Square Grid Problem, Edwin Aviles, 1964-65, The Irwin S. Chanin School of Architecture Archive)

formed the core of studio teaching under Hejduk and are named according to the primary pedagogical tool they address: the Nine Square, Cube, and Juan Gris Problems.

Hejduk also put in place a fourth studio, the Analysis Problem. It examined exemplary buildings or projects from the history of the discipline (see Franzen et al., p. 245-262). This fourth studio is not examined below. In the following I survey the three core studios and sample student work from each.

In notes from 1965, Hejduk describes the first of these studios as follows: 'The Nine-Square problem is used as a didactic tool for the introduction of architecture... A[n] understanding of elements in their primary essences is revealed; the idea of fabrication emerges' (Hejduk, 2011, s.p.).

The Nine Square Problem starts from the subdivision of a square into nine others. The student develops a plan, an isometric, and a model proceeding through a series of exercises. In so doing, according to Hejduk, elements (grid, frame, post, beam, panel), relations (center, periphery, field, edge, butt, interlock, compression, tension, extension) and conditions (measurement, number, black, white, gray) are revealed and tested (see Hejduk, 2011 s.p.; Franzen et al., 1999, p. 23; Moneo, 1980, p. 65).

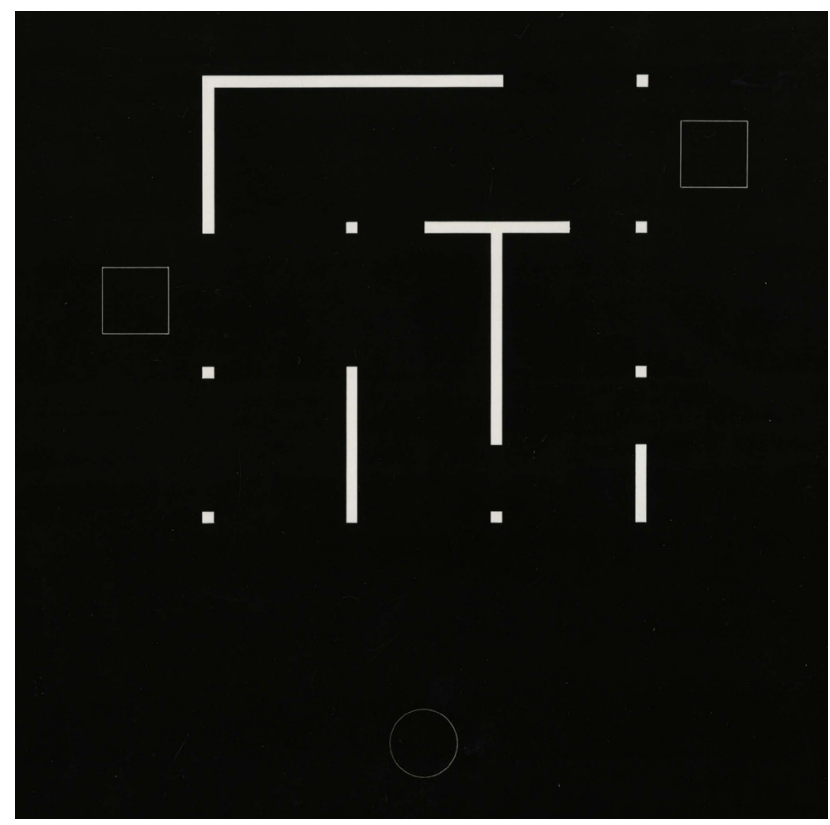

Figure 2: The Nine Square Problem, Plan variation on a black field (Architectonics, The Nine Square Grid Problem, Diana Viorica Georgescu, 1970-71, The Irwin S. Chanin School of Architecture Archive)

A resulting studio project (see Figure 1) provides a snapshot of certain of the architectural problems under investigation: post to partition relations, edge to field or frame to boundary and the differences of these one to the other, of implied direction whether of release or containment.

Refinements in the response to the problem reveal the potential of this apparently simple exercise. Questions of direction, energy and the act of drawing - including figure/ground oscillations - emerge. For example, in Georgescu's solution, the reversal of background and 'figure' can be claimed to highlight the spatial and structural forces that result from combinations of column/post, I, L and T elements (See Figure 2).

Closely related to the Nine Square problem, and introducing an appropriate level of complication, is the Cube problem. The design studio brief can be succinctly stated: given a cube thirty feet to a side, invent a proposal. The Cube Problem, or a form in search of a function. A logical extension of the elements and form relationships worked on in the previous studio, it now starts to engage three-dimensional conditions more overtly and with color. See for example Schiano's early work from the studio (Figure 3). One also reveals here an engagement with the act and traditions of drawing itself as a legitimate field of inquiry. The cube's frame, implied 


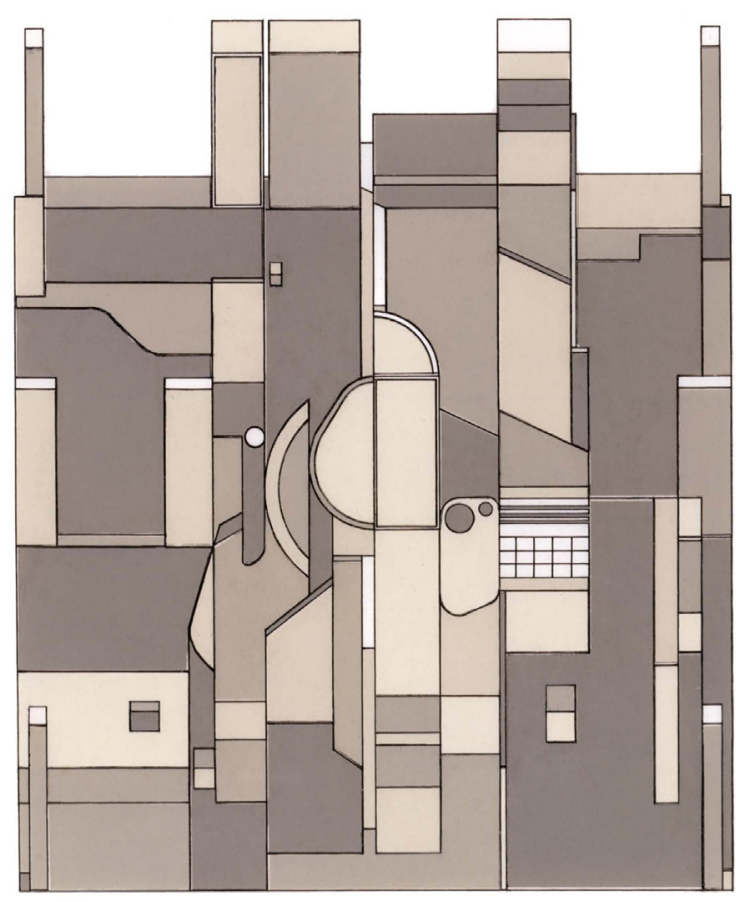

Figure 3. The Cube Problem (Thesis, Kenneth A. Schiano, 196970, The Irwin S. Chanin School of Architecture Archive).

or real, also allows the studio member to test out new notions including carving or cutting, projection and extrusion, collapse and explosion.

Ceraldi's thesis project (Figure 4) illustrates certain potential findings. Drawing style and representation are specifically in play (folded elevations). The onedge or frontal unfolded axonometric and exploded drawing condition is another instance of what might result from the none-too-innocent brief.

The third of the core Hejduk studios was the Juan Gris Studio. The brief asks students to design a building 'in the intention of Juan Gris' (Franzen et al., 1999, p. 193). Architectural states of transparency, of simultaneity, and of organic and technocratic or machined form are called up. If we look at examples of student projects, the nature of the findings and their difference from the preceding studios is made clear.

The most striking difference is the increased complexity in the devices and instruments at work. In the House by Colamarino for example (Figure 5), ideas of circulation and simultaneity are clearly present. A sense of time or memory thus enters.

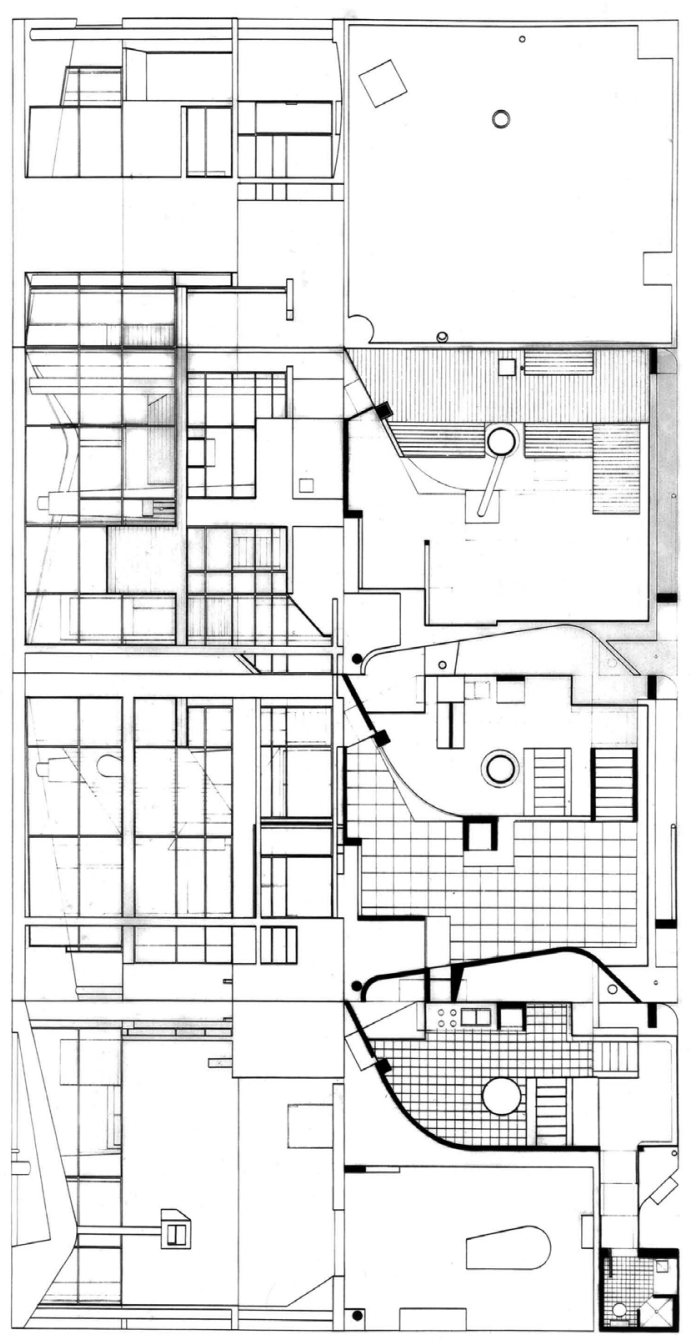

Figure 4: The Cube Problem - unfolded direction project elevation and plan (Thesis, An Experiment in Architecture, Theodore Michael Ceraldi, 1969-1970, The Irwin S. Chanin School of Architecture Archive).

And in Dolinski's project (Figure 6), engagement with site, thought of perhaps as entourage, emerges, even if a real place is still not part of the agenda. Whereas the Nine Square and Cube studios generally produced research on form relationships bound to an architectural object, the Gris studio now starts to engage and impact on a site, or at least an outside field however virtual or implied it may be. What is also evident in this third studio is a shared studio vocabulary, of shapes and formal-spatial relations including the piano form, line, square, circle, circular post, free plan, and free distribution.

As a provisional summary, Raphael Moneo provides a useful synthesis of the outcomes or intent of Hejduk's pedagogical approach. He claims for it both 
close-by and far-reaching stakes. The three Hejduk studios are 'exercises', a limbering of the hand and mind and eye. And they as a result together have a distinctly pedagogical function, one distinctly appropriate to an undergraduate studio. I think there is also an epistemological role.

Different from the studios of Rowe, Hejduk designed studio problems for undergraduates, thus the Nine Square problem was intended for first year students.
Moneo continues, now less about the studio's impact on the student and more on the general context in both practice and theory in which the work should be interpreted: 'does the formal structure of architecture come as a result of making an abstract, modular division of space or does it, on the contrary, arise as an independent assertion making use of elementary images and figures?' (Moneo 1980 , p. 65, 67). For Pérez-Gómez, it is the promotion and production of imagination that is the main thing (Pérez-Gómez 1999, p. 16-17).
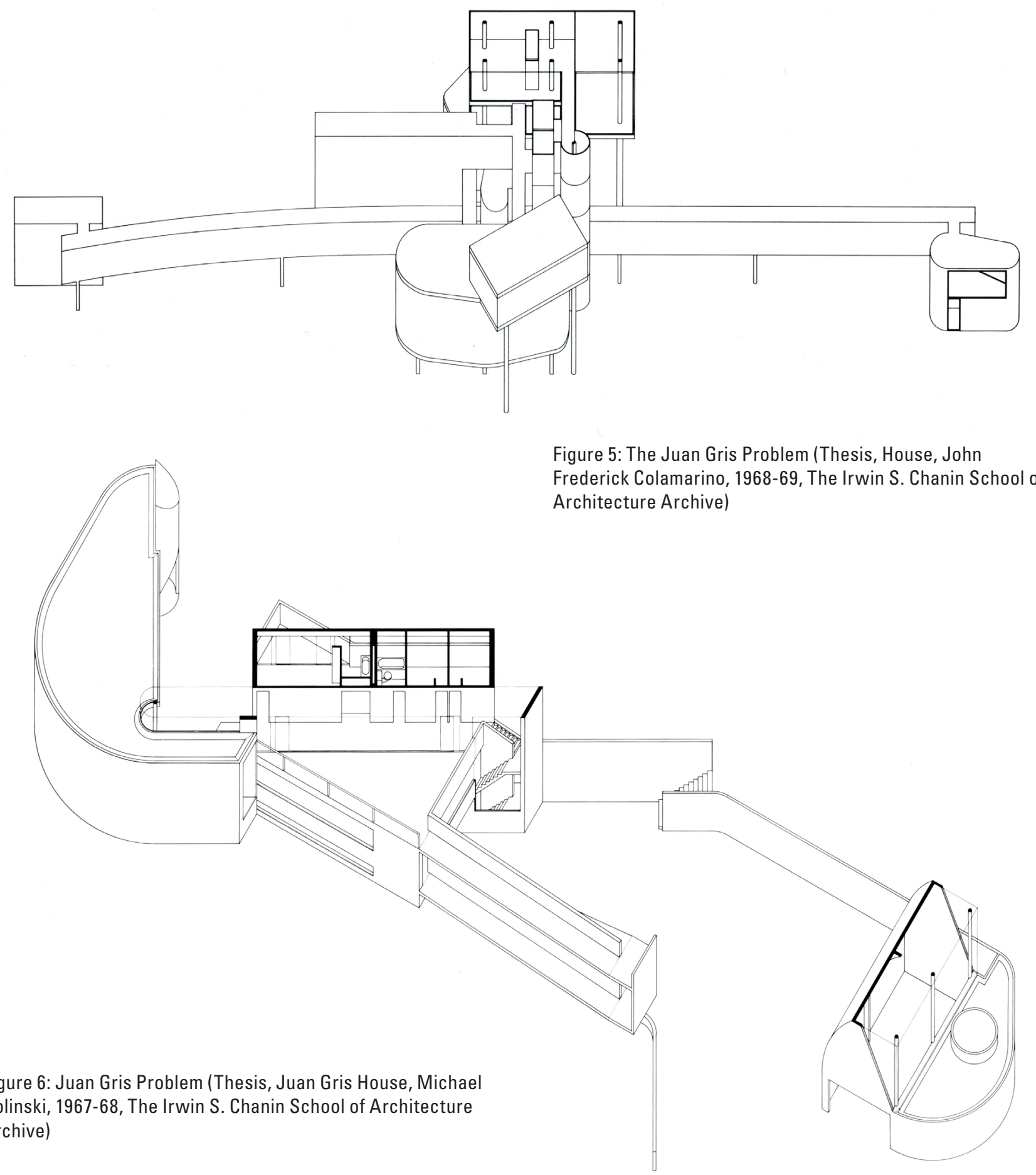


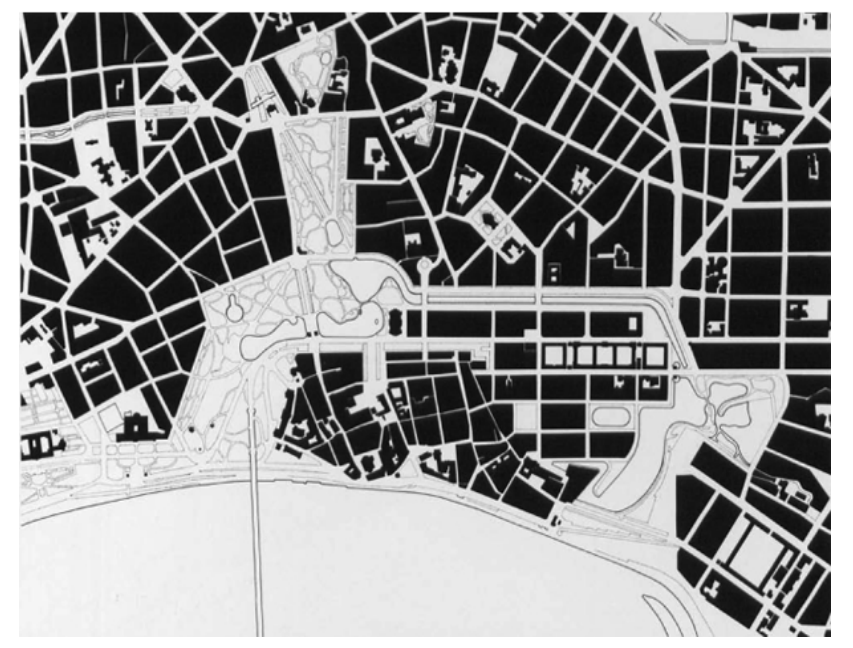

Figure 7: Mapping and analysis study of Düsseldorf. Figure/ Ground plan (Wayne Cooper, 1967, Cornell University, Department of Architecture)

\section{An Urban Design Studio}

Under Colin Rowe, and over a roughly twenty-fiveyear period, the postgraduate Urban Design Studio at Cornell University took urban scale elements as the site of invention and of intervention. The formal development of the city was it's field of investigation.

A founding hypothesis informed at a basic level all of the studio work: that of the integration - dynamic, antagonistic, dialectical - of the traditional city and the modern city, the city of solids and that of voids. The design studio was distinguished by a series of relevant problems and an attitude 'loosely defined as contextualism' (Middleton 1980, p. 47).

As described by Robin Middleton, a student of Rowe's, in his introduction to the student projects reproduced in the second issue of The Cornell Journal of Architecture, a limited range of project types were explored (Middleton, 1983). Such project types included waterfront sites, impacted grid collisions, field/edge ambivalence, and produced responses that included linear buildings, towers, towers and podiums, and perimeter blocks. Open space - shaped or otherwise given texture and figure - became a response to the research problems in certain studios. A selection of projects follows which captures aspects of the studio character and a view of what was at stake. These include grid
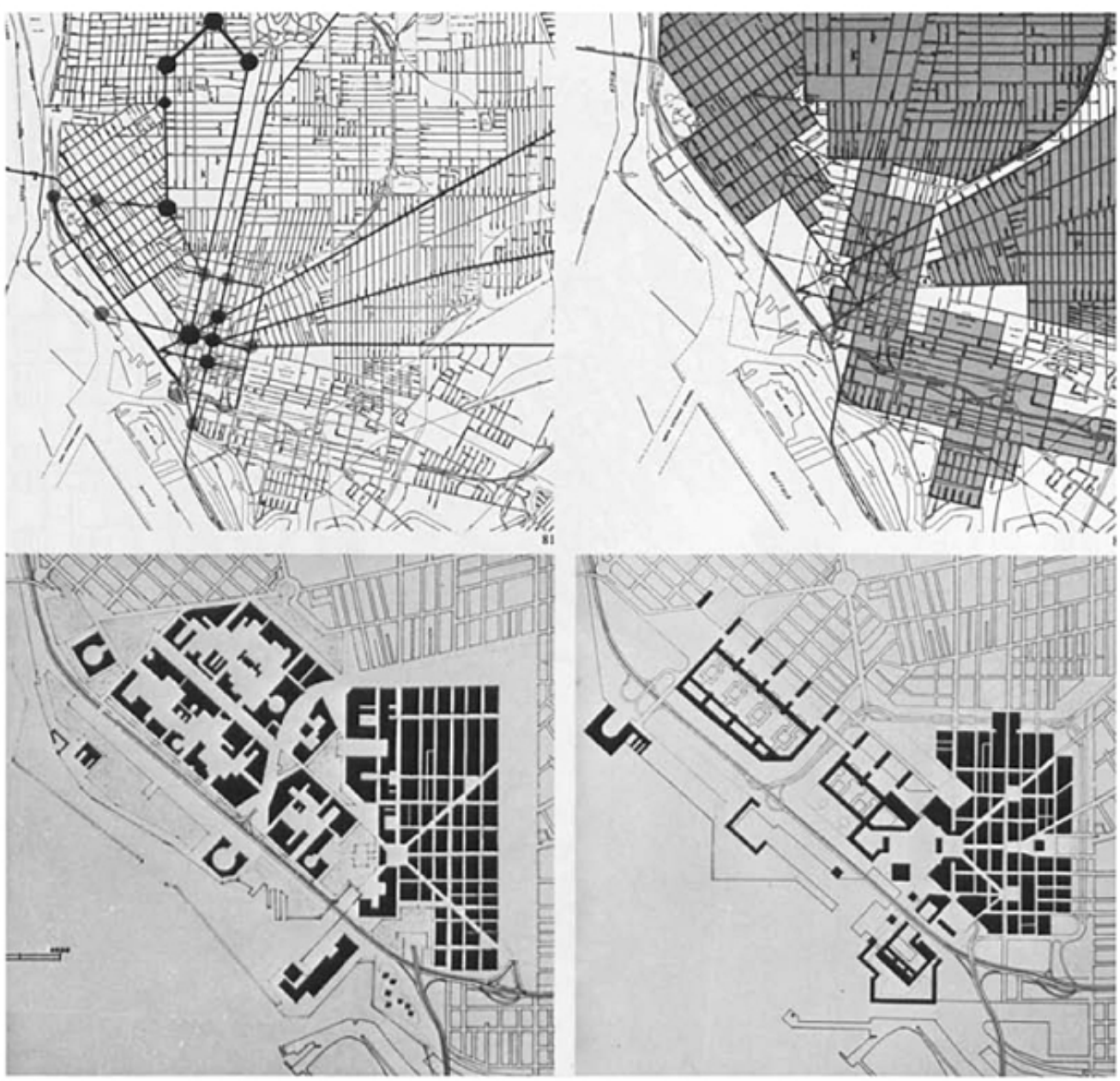

Figure 8: Grid collisions: study of the Buffalo Waterfront, a group project (R. Baiter, R. Cardwell, D. Chan, W. Cooper, H. N. Forusz, A. H. Koetter, M. Mik, E. F. Olympio, F. R. Oswald, 1969, Cornell University Department of Architecture) 


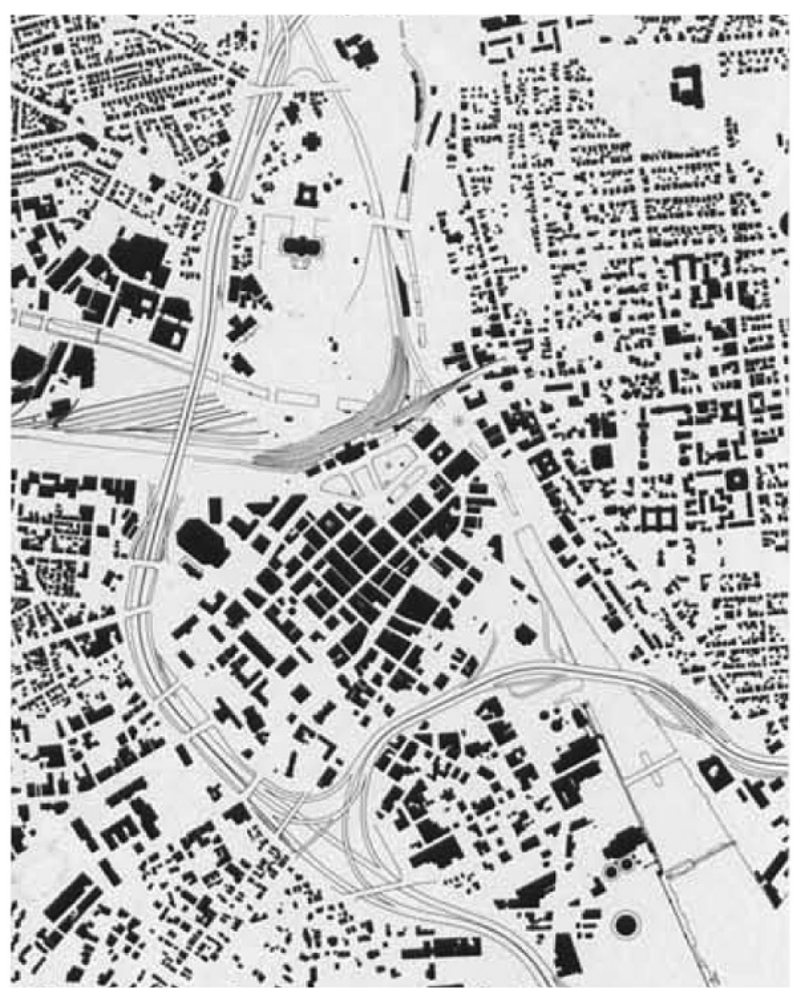

Figure 9: Infill and completion: open space as figure and ground, Providence existing and proposed plans (Providence: Capital District Development Strategy, D.B. Middleton, 1980, Cornell University, Department of Architecture)

collisions, and the use of figure/ground as the predominant realm of representation and investigation.

Key examples of project types illustrate the kinds of studio problems assigned by Rowe and the range of research outcomes considered. From a review of published projects, three kinds of design studio problems were undertaken:

- grid and fragment studies largely explored at the scale of the street and block plan

- infill or connection or completion problems, taken on at the scale of the composite building or group plan

- overall (field, city precinct) plans that may include open spaces of various kinds as a key ordering device such as water, park, plaza, garden

I will in what follows describe key elements and examples of each, recognizing that often the studio blurred the boundaries of these artificial categories.

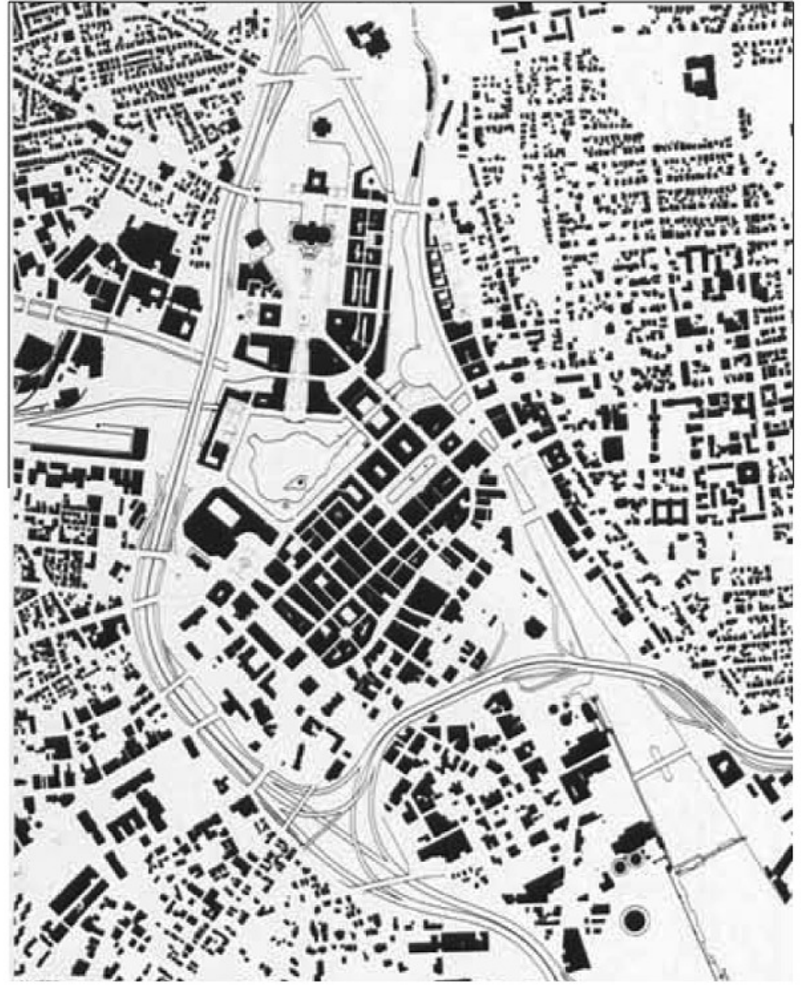

Figure 10: Composite building generated from field and edge study: Marylebone Rail Station, Regent's Park London, Figure/Ground Plan (Steven Fong, 1979, Cornell University, Department of Architecture)

Cooper's figure/ground plans summarize both an analytical tool and a representation/design approach (Figure 7). It appears as a constant resource and beginning point over the decades. Two particularly clear examples of the limits and beauty that could result can be seen in Cooper's study of Düsseldorf and in the suite of drawings prepared around the Buffalo waterfront problem (Figure 8).

The group plan and the composite buildings were prevalent for many years both as condition for analysis and as an ideal to work toward, reflecting in part the precedent based assumptions in some studio years (Figures 9 and 10 ).

A review of published studio work as well as Rowe's academic publications reveals his unflagging return to this problem, and to the devices that were deployed to resolve even provisionally the assigned brief.

Infill and hinge or connection conditions are favorites of this studio study. In the Providence Capital District studio, for example, can be seen a full range of urban scale problems including loss of spatial 


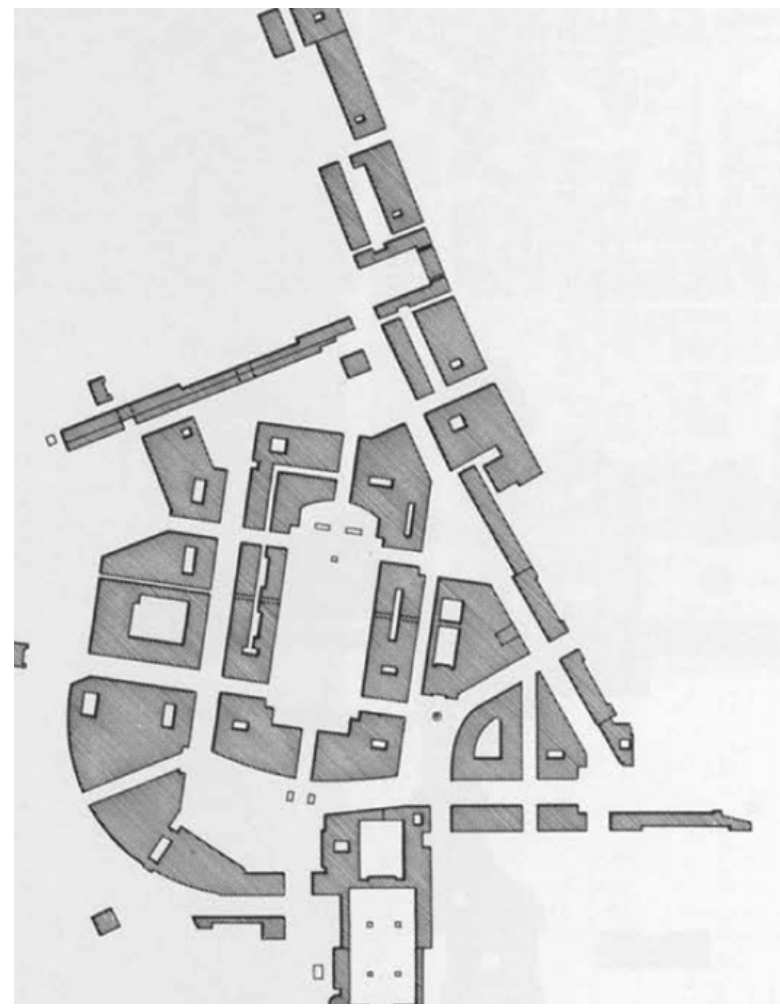

Figure 11: Field/edge research and proposed infill plan: Berlin Tiergarten (R. Carvalho, D. Frederick, E. Sennyey, 1981, Cornell University, Department of Architecture)

definition, small to large scale, and foreground to background. Fong's solution to the Marylebone studio is a particularly elegant example of the both figure and ground aim (Figure 10).

A larger field - whether of the city or of open space more generally - populate the studio work in later years. In the research toward a transition or transformation from figure/ground to Nolli-type drawings - and the larger field more generally - one can discern a change in perspective.

The parallel publications by Rowe and Koetter of Collage City to a more subtle degree provide another formulation of the research intent and reach (Rowe

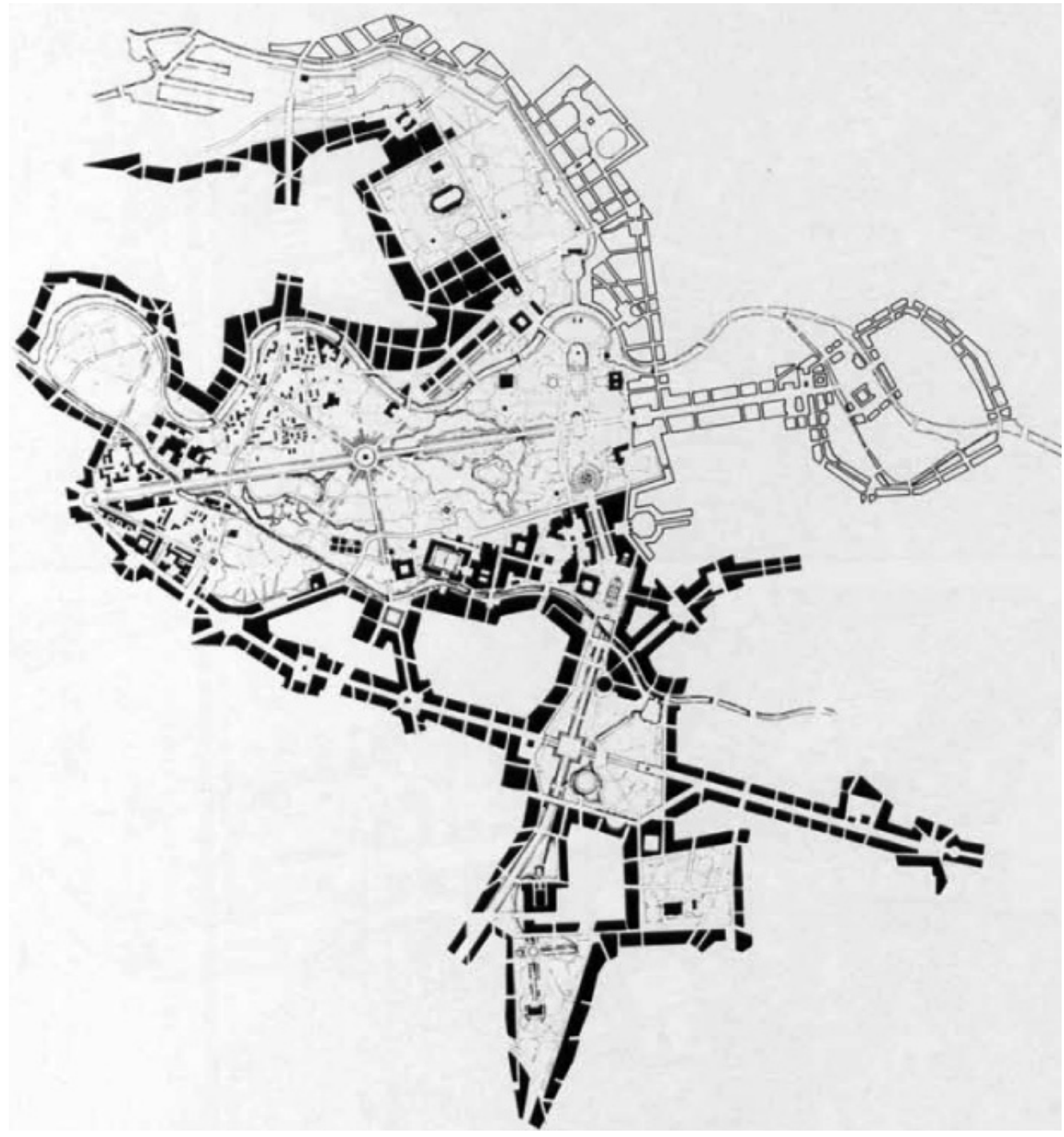

Figure 12: Completion/ extension of an existing traditional city: proposed extension plan, Florence (B. Lonnman, 1980, Cornell University, Department of Architecture) 
and Koetter 1978). Underlying the whole endeavor as noted at the beginning is the engagement with modern architecture and the traditional city and the founding question: can modern architectural types be used to solve traditional urban problems?

Berlin, Rome, Providence, Florence, London provided the material for much of the studio work in this period. And the group project was not uncommon. Infill may be the most easily legible term, but a close study of, say, the Florence plan of Lonnman, reveals a now mature resolution of this fine-grained approach (See Figures 11 and 12).

From the above too brief review, it can be claimed that the following constants distinguish Rowe's urban design studio:

- conceptualizing the city as a (single) gestalt

- engaging with a corpus of architectural/urban forms

- collage as a general composition strategy

- employing techniques of abstraction, thus a limited number of drawing styles, with figure/ ground leading the way

- work and re-work from previous studio efforts

- a limited number of design problems: figure, field, pattern texture, edge, axis

There is, in addition, a clear bias to be inclusive and to privilege conjecture.

\section{CONCLUSIONS}

Two approaches to the university architecture studio have been briefly surveyed. What, if anything, do they share and what are the important differences? And what of the opening proposition that each provides a model for studio-based research?

Both Hejduk's and Rowe's efforts, to state the most basic, can be read as investigations of specific architectural-urban problems, whether work on architectural imagination, the traditional/modern city dialectic, or the design process itself and more generally.

Looking more pointedly, five characteristics, at least, seem to be in common.
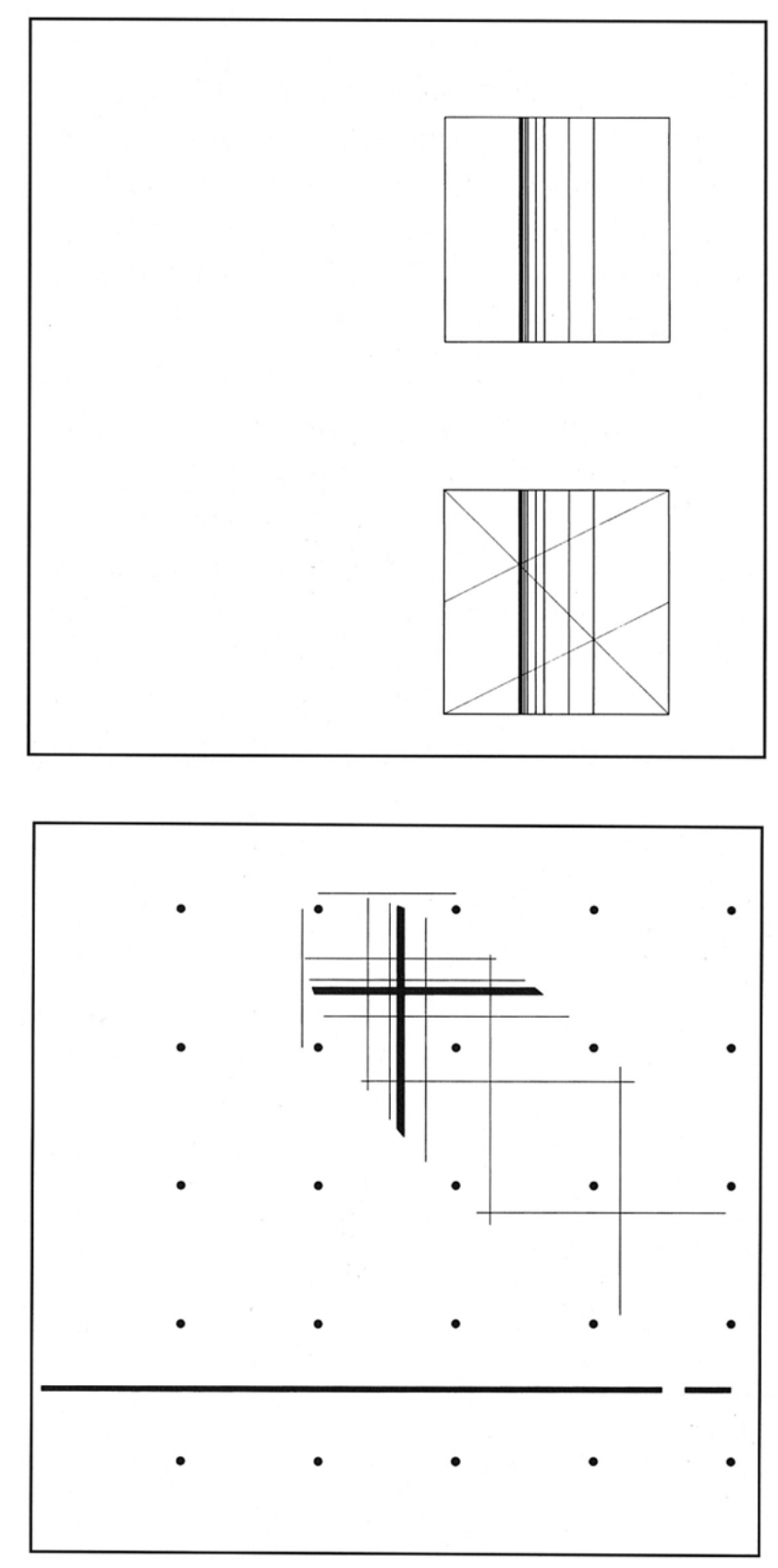

Figure 13: The most radical exploration of the cube problem, according to Hejduk (Thesis, A Twenty-Seven Foot Cube, Peter Saltini, 1969-70, The Irwin S. Chanin School of Architecture Archive)

- First, the functional brief or space program is downplayed or even absent. Hejduk assigns no functional brief and Rowe downplays function over a privileging of the gestalt, that is of eclectic and coherent shape or form

- Second there is an emphasis on precedent, or in the case of Hejduk's first year undergraduate student in front of the Nine Square problem, the strict delimitation of discipline-specific architectural elements 
- Third is repetition: the studio problems are repeated over several years with subtle variations and refinements. In the case of Hejduk's Cooper Union studios, a framework is adopted and replacement terms (of concept couple, analytic component, site) introduced. So duration and the implicit studio culture is another shared characteristic

- Fourth, there is an explicit effort to remain open to the new, and to renewal generally. In the case of Hejduk, perhaps at the level of individual imagination. For Rowe, the force of a specific city or urban scale place to reshape our thinking and forms

- There is a fifth aspect, related to transmission and reflection: the findings or outcomes are documented. In the case of Hejduk, public exhibitions and publications, along with the requirements of accreditation to record and archive, in part spurred the systematic documentation of student projects. At Rowe's Cornell, a cluster of articles by graduates and colleagues framed critical discussions around the studio and the eventual publication of a high number of projects

The differences are both evident and subtle. The scale of investigation is the most visible. Studio assignments ranged from the post-beam joint at Cooper Union to the city under Rowe.

An attitude toward context varies, as does the underlying assumption about autonomy. The studio projects that emerged out of Cooper Union are a work on the language of architecture, and the pedagogical intent through paradigmatic problems is to study the most normative of architectural relations.

At a different scale and in a different realm - that of the city-Rowe's deployment of figure/field relationships passes through a filter or is indexed against cubist composition devices not only in plan but spatially, which endeavor to realize an 'and-and' as different from an either or condition. Rowe's field of inquiry can be seen to be simultaneously context based - whether Rome, Baltimore or Manhattan and deeply engaged with architecture's future by a parallel confrontation with architecture's past (its insides) and an openness to the potential for architecture to engage with concepts and ideas from other realms.

Another way to distinguish the difference of the two approaches, and to clarify their contribution to the question of design-led or studio-based research, is to endeavor to formulate the research problem each could be said to be treating.

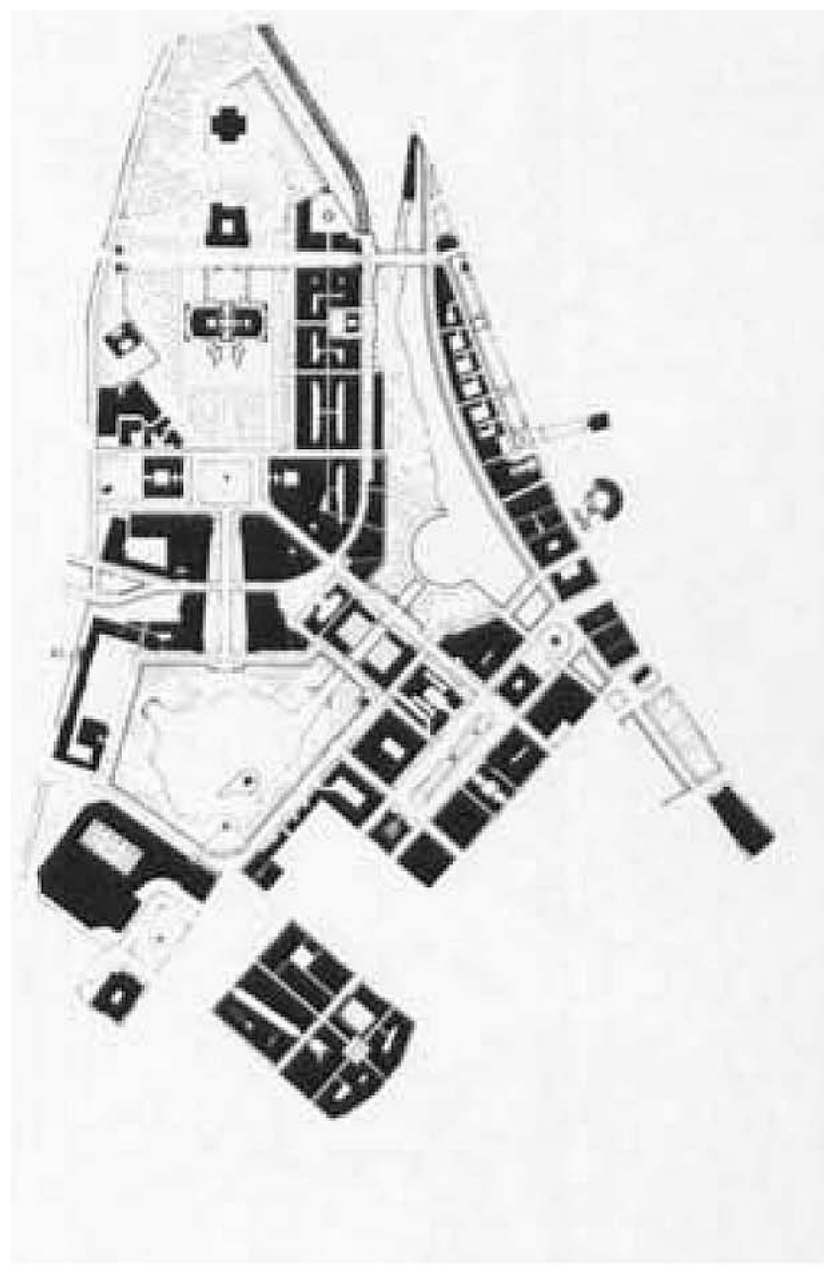

Figure 14: Studies of alternate field and object readings of open space, Providence: Capital District Development Strategy (D. B. Middleton, 1980, Cornell University, Department of Architecture)

For Hejduk, he himself has given us the most succinct formulation: the design studio, in fact the pedagogical charge in the largest sense and as noted earlier, is to 'search for new relationships of form.' The scale of form research in his suite of studios focused on the joint, post and beam relationships, and frame to grid oppositions. It is a limbering up, an exercise. In this, and keeping in mind the insistence on abstraction from the citation that opened this paper, Saltini's might be taken as an extreme version (Figure 13).

For Rowe's ideal studio, perhaps the research problem is that of reconciling traditional city form and modern architecture. Here the form research is emphatically at an urban scale and conclusions, however provisional, do result. Think of the role of the linear building, or that of composite buildings, the discovery of the figure/ground drawing as tool, and its complication through Nolli. And now perhaps that double acknowledgment of disciplinary tradition 
and those modernist 'novelties' referenced by Rowe, and cited at the beginning of this paper, find their place (Figure 14).

Different from traditional kinds of scholarly work on form and thought in architecture, the Hejduk and Rowe studios can be read as efforts to undertake research through the activities of the studio. In this, and returning to the opening proposition, they can thus be claimed to provide model approaches to the university studio as an emphatic site of research, and the above examination a contribution to debates around design-led research in architecture.

\section{ACKNOWLEDGMENTS}

The research and writing of this paper was undertaken with the support of the University of Canberra Architecture program and I want to acknowledge Professor Lyndon Anderson, Dean of the Faculty of Arts and Design, and successive Heads of Discipline Professor Peter De Deckker, Associate Professor Eugenie Keefer Bell, and Professor Gevork Hartoonian, for their on-going support. A preliminary version was presented at the international design conference Nordes 2013 Experiments in Design Research: Expressions, Knowledge, Critique, June 9-12, 2013, Copenhagen. The paper has benefited from the careful review and engaged comments of anonymous readers. Partial financial support to participate in the June conference was provided by the University of Canberra, Faculty of Arts and Design 2013 Conference Fund for which I am grateful.

\section{ILLUSTRATION CREDITS}

Figures 1-6, 13. Images of student work from The Cooper Union, Copyright (c) 2012 The Irwin S. Chanin School of Architecture Archive

Figures 7-12, 14. Images of student work from Cornell University, Copyright (C) Cornell University, Department of Architecture

\section{REFERENCES}

Cooper, W. (1983). The Figure/Grounds. The Cornell Journal of Architecture, 2, 42-53.

Franzen, U., Pérez-Gómez, A., \& Shkapich, K., (Eds.). (1999). The Education of an Architect: A Point of View, The Cooper Union School of Art \& Architecture. New York: The Monacelli Press, Inc. (The original version was published in 1971 and reissued in 1999 in a slightly smaller format).

Hejduk, J. (1974). Fabrications. New York: The Cooper Union School of Art \& Architecture.
Hejduk, J. (1985). Centralized Relief Upon a Tableau. Cooper Union Foundation Building Renovation. In Shkapich, K. (Ed). John Hejduk Mask of Medusa Works 1947-1983. New York: Rizzoli, 66-67.

Hejduk, J. (2011). The Nine Square Problem - from the Collection of the School of Architecture Archive. Architecture at Cooper, Newsletter of The Irwin S. Chanin School of Architecture for 2010-11, 5, s.p.

Hurtt, S. (1983). Conjectures on Urban Form. The Cornell Urban Design Studio 1963-1982. The Cornell Journal of Architecture, 2, 54-78.

Maxwell, R. (2010). Rowe's Urbanism in Collage City: A Triumph for Common Sense. In Marzo, M (Ed.). L'architettura come testo et la figura di Colin Rowe. Venice: Marsilio, 154-169.

Middleton, D. B. (1980). The Combining of the Traditional City and the Modern City. Lotus International, 27, 47-62.

Middleton, D. B. (1983). Studio Projects. The Cornell Journal of Architecture, 2: 78-141.

Moneo, R. (1980). The Work of John Hejduk or the Passion to Teach. Architectural Education at Cooper Union. Lotus International, 27, 65-85.

Pérez-Gómez, A. (1999). Education of an Architect: Unraveling a Point of View, 1999. In Franzen, U., Pérez-Gómez, A., \& Shkapich, K., (Eds.), The Education of an Architect: A Point of View. New York: the Monacelli Press, Inc., 14-19.

Rowe, C. (1996a). Architectural Education: USA. In Caragonne, A., (Ed.), As I Was Saying: Recollections and Miscellaneous Essays. Cambridge, Mass.: The MIT Press, Volume 2, 53-64.

Rowe, C. (1996b). Cornell Studio Projects and Theses. In Caragonne, A. (Ed.), As I Was Saying: Recollections and Miscellaneous Essays. Cambridge, Mass.: The MIT Press, Volume 3, 5-84.

Rowe, C. \& Koetter, F. (1978). Collage City. Cambridge, Mass.: The MIT Press.

Slutzky, R. (1980). Introduction to Cooper Union. A Pedagogy of Form. Lotus International, 27, 86-104.

\section{CORRESPONDENCE}

Michael Jasper, University of Canberra, Faculty of

Arts \& Design, ACT 2601 Australia

E-mail:michael.jasper@canberra.edu.au

Published online 31 December, 2014

ISSN 1749-3463 print/ISSN 1749-3471

DOI: 10.14434/artifact.v3i2.3969

(C) 2014 Artifact 